\title{
FEATURES OF MATHEMATICAL THINKING AMONG FINNISH STUDENTS IN UPPER- SECONDARY SCHOOL
}

\author{
Jorma Joutsenlahti
}

Department of Teacher Education

University of Tampere

Finland 


\section{- Introduction}

- Theoretical framework

- Aim and perspectives

- Results 


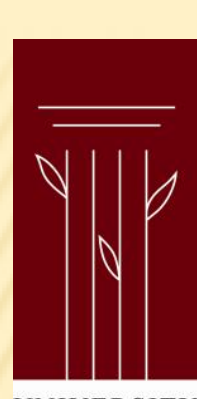

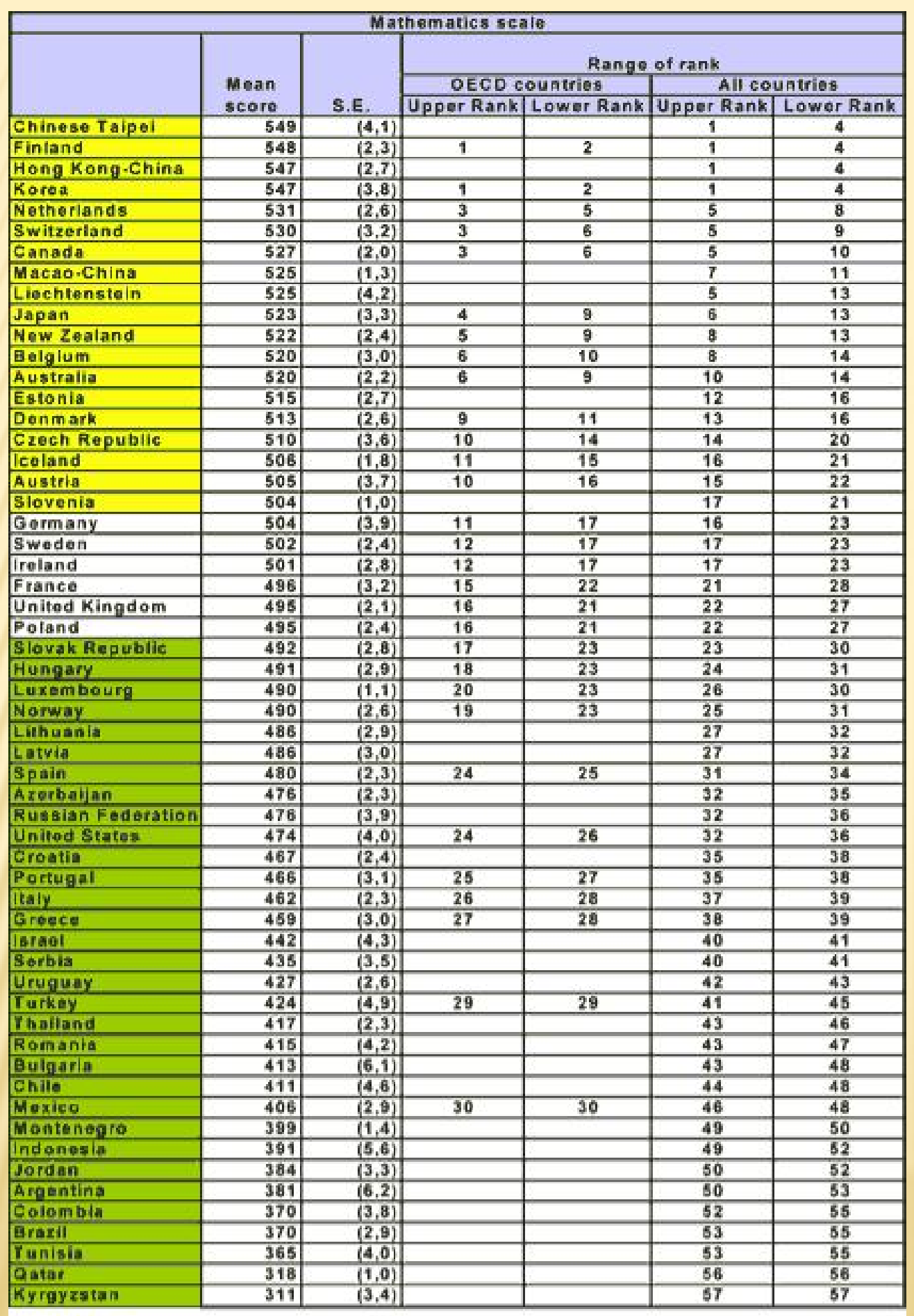

Statistically significantly above the OECD average

Not statisticaliy signifficantily different from the OECD average

Statissically significantly below the OECD averago
Could we expect as good results in

mathematics also

in Finnish uppersecondary schools?

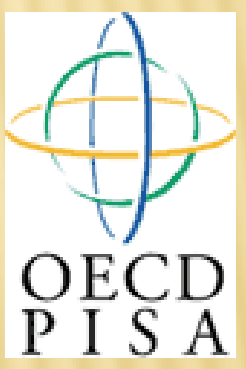

Finland and Korea, and the partners Chinese Taipei and Hong Kong-China, outperformed all other countries/economies in PISA 2006. 


\section{- Introduction}

- Theoretical framework

- Aim and perspectives

- Results 


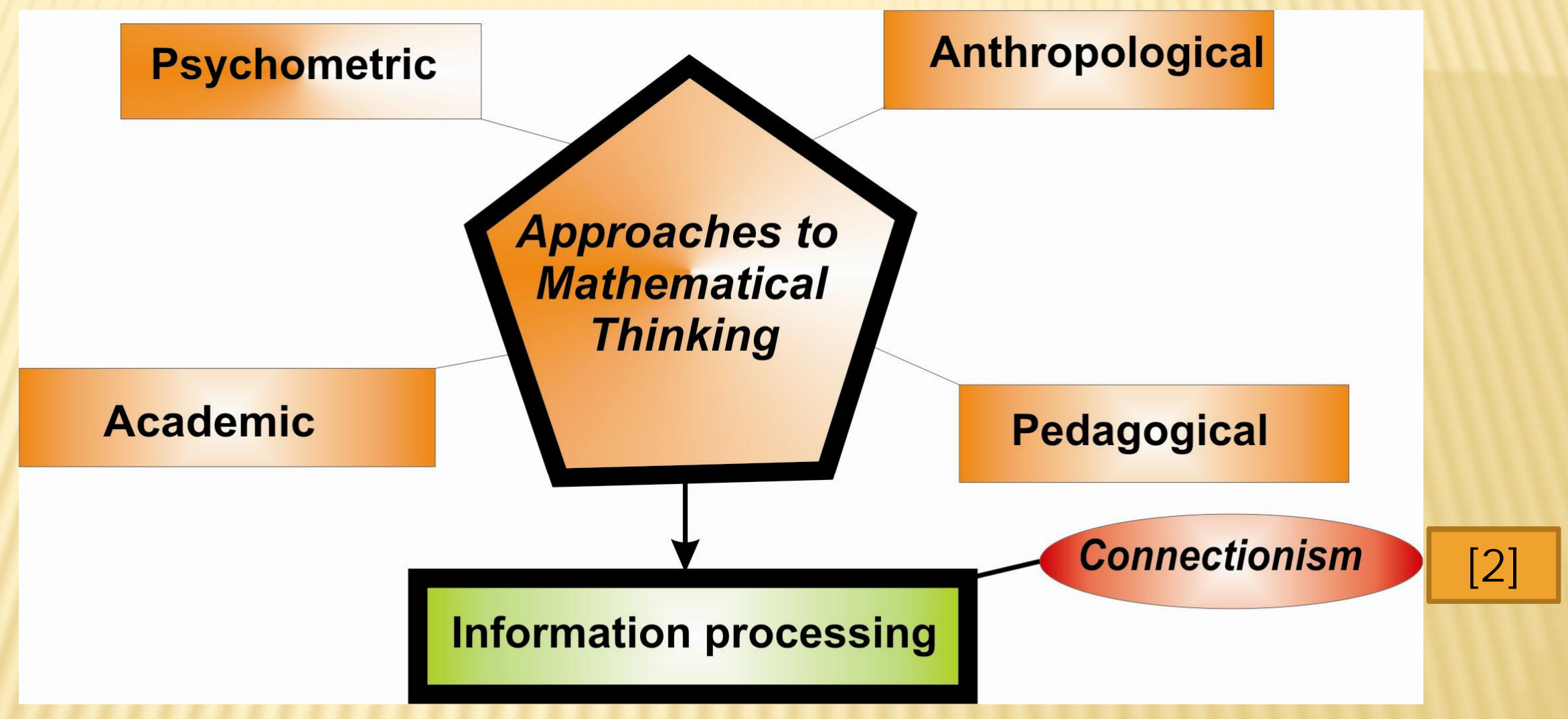




\section{Knowledge}

Psychological epistemology

Philosophical epistemology

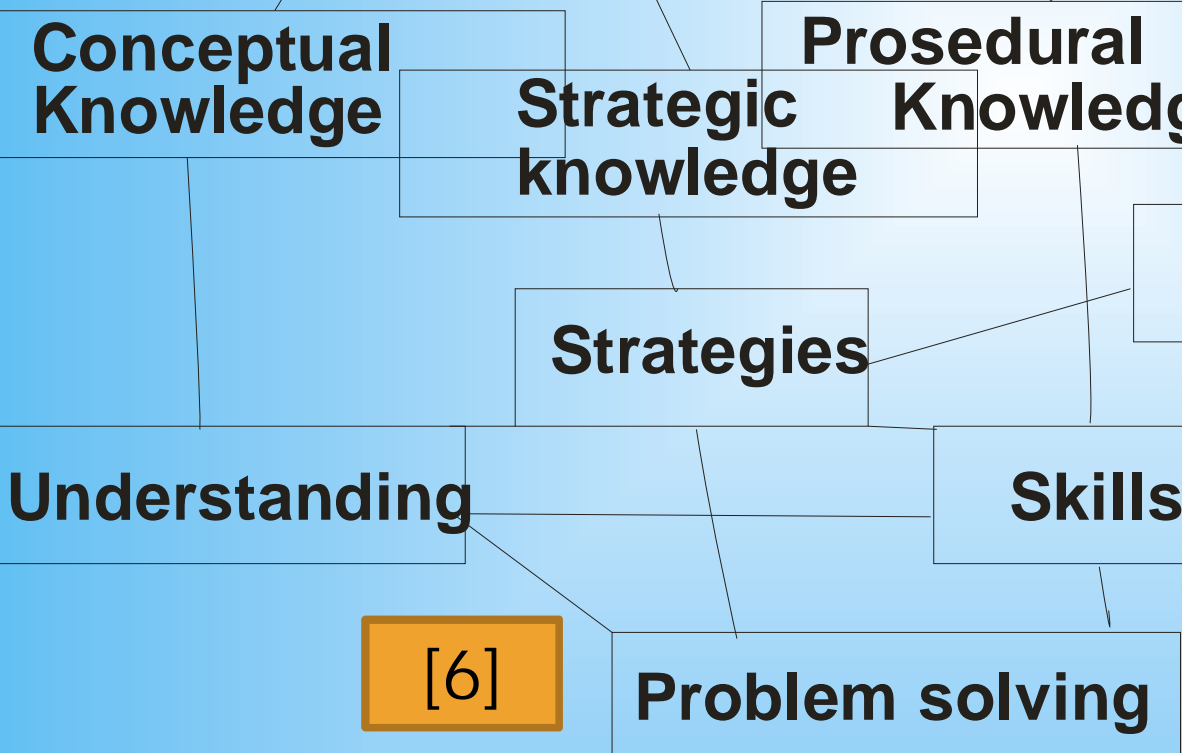

THEOREICAL FRAMEWORK 2/ 4 

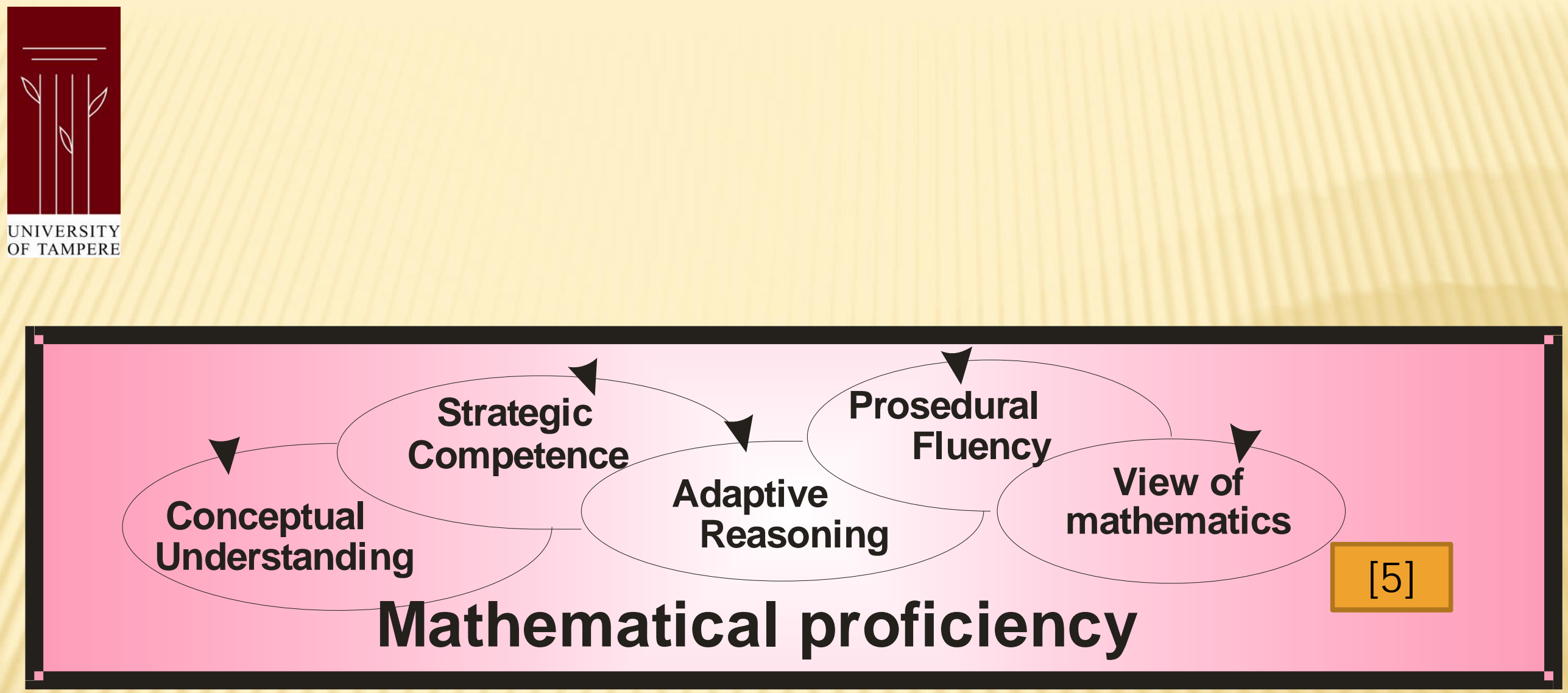

[7] 

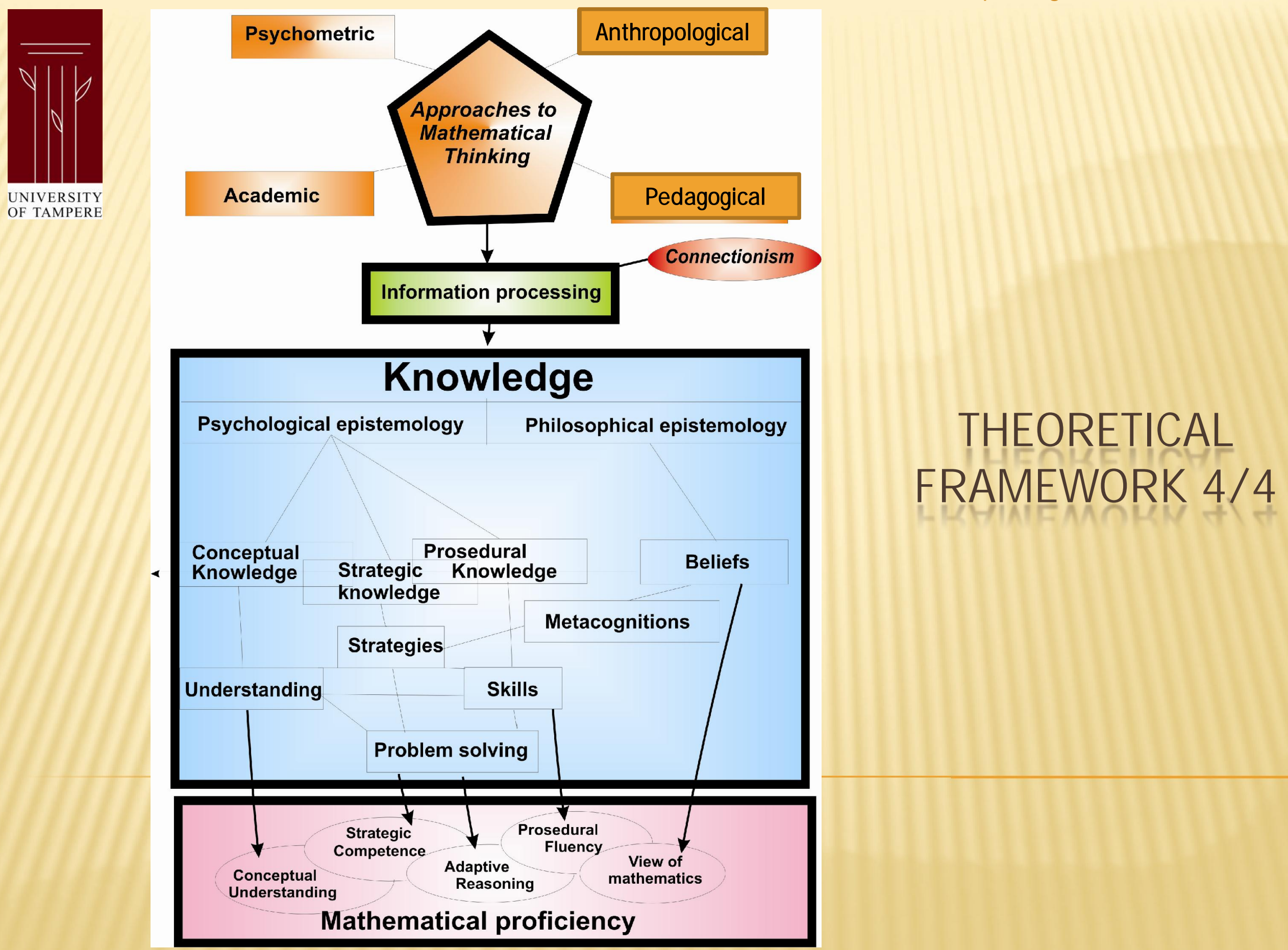


\section{- Introduction}

- Theoretical framework

- Aim and perspectives

- Results 


\section{AIM OF THE STUDY}

OF TAMPERE

The main problem in the study is to describe features of the student's mathematical thinking

The sub problems consider what kinds of differences exist in the mathematical proficiency and in the view of mathematics between genders and between students who chose a compulsory test or an optional test in the matriculation examination. 
Societal

UNIVERSITY

OF TAMPERE

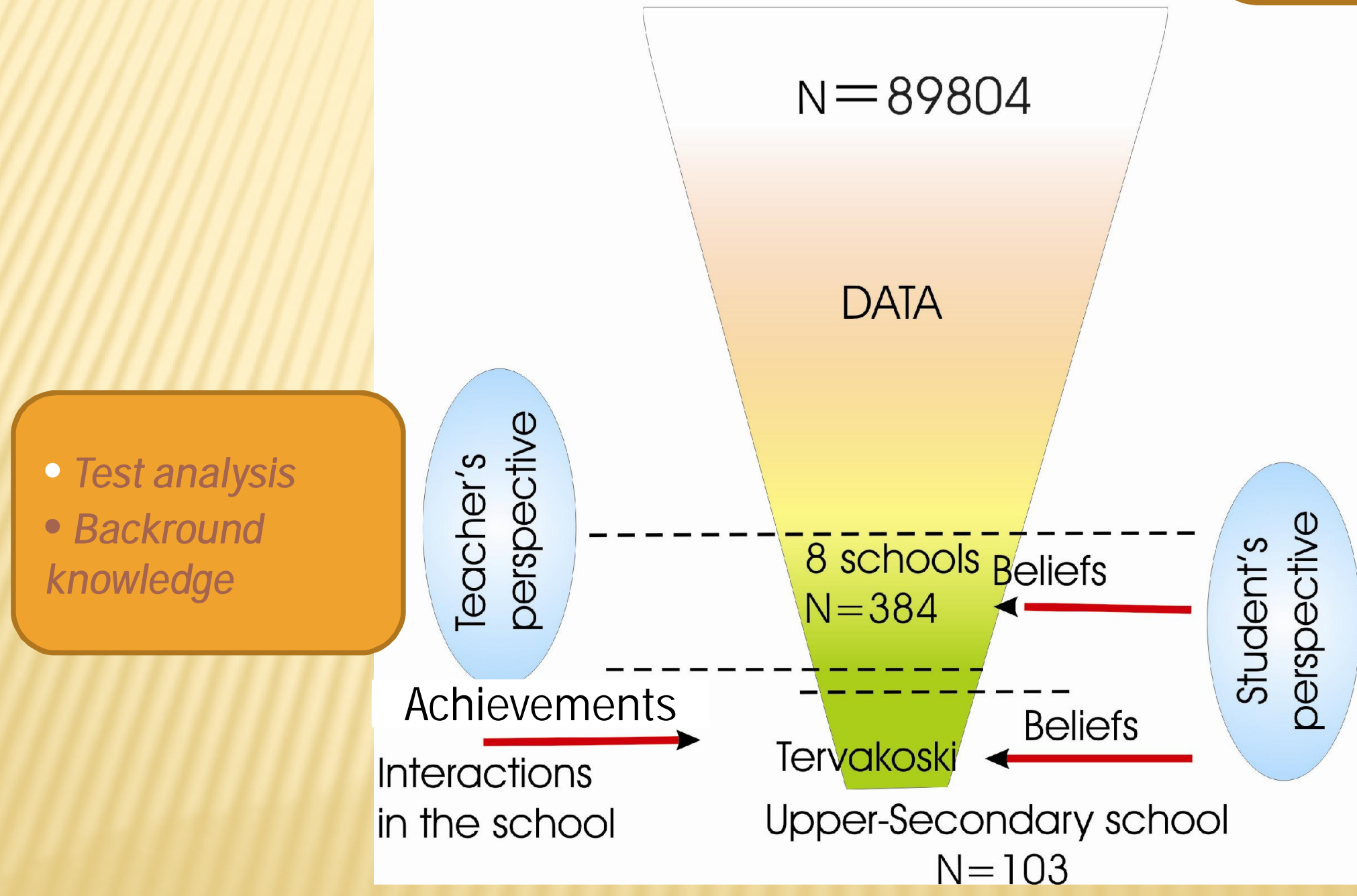

perspective

Three perspectives

\section{-Results}

-Item analysis
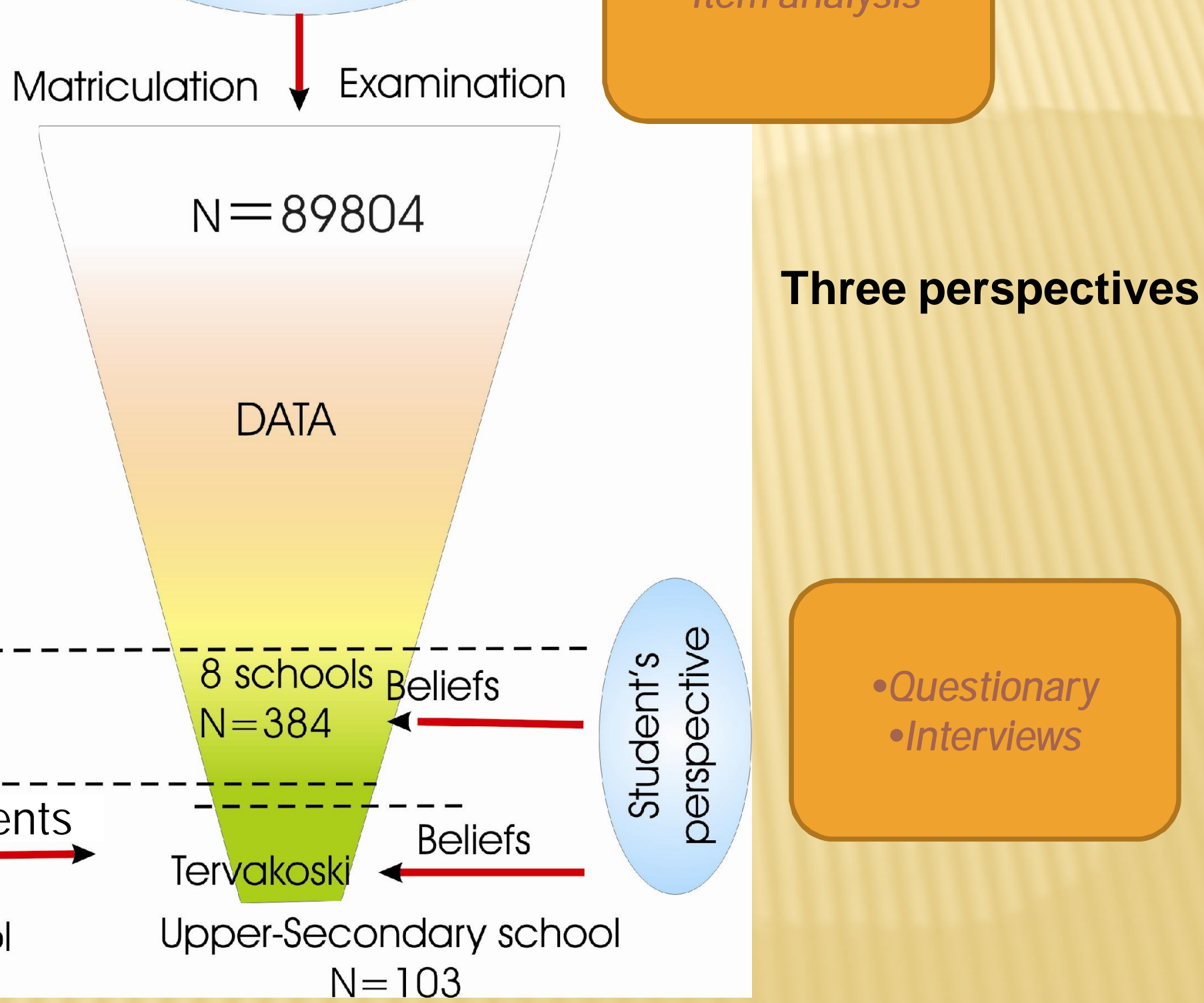


\section{TWO-BY-TWO FREQUENCY TABLE}

Societal perspective

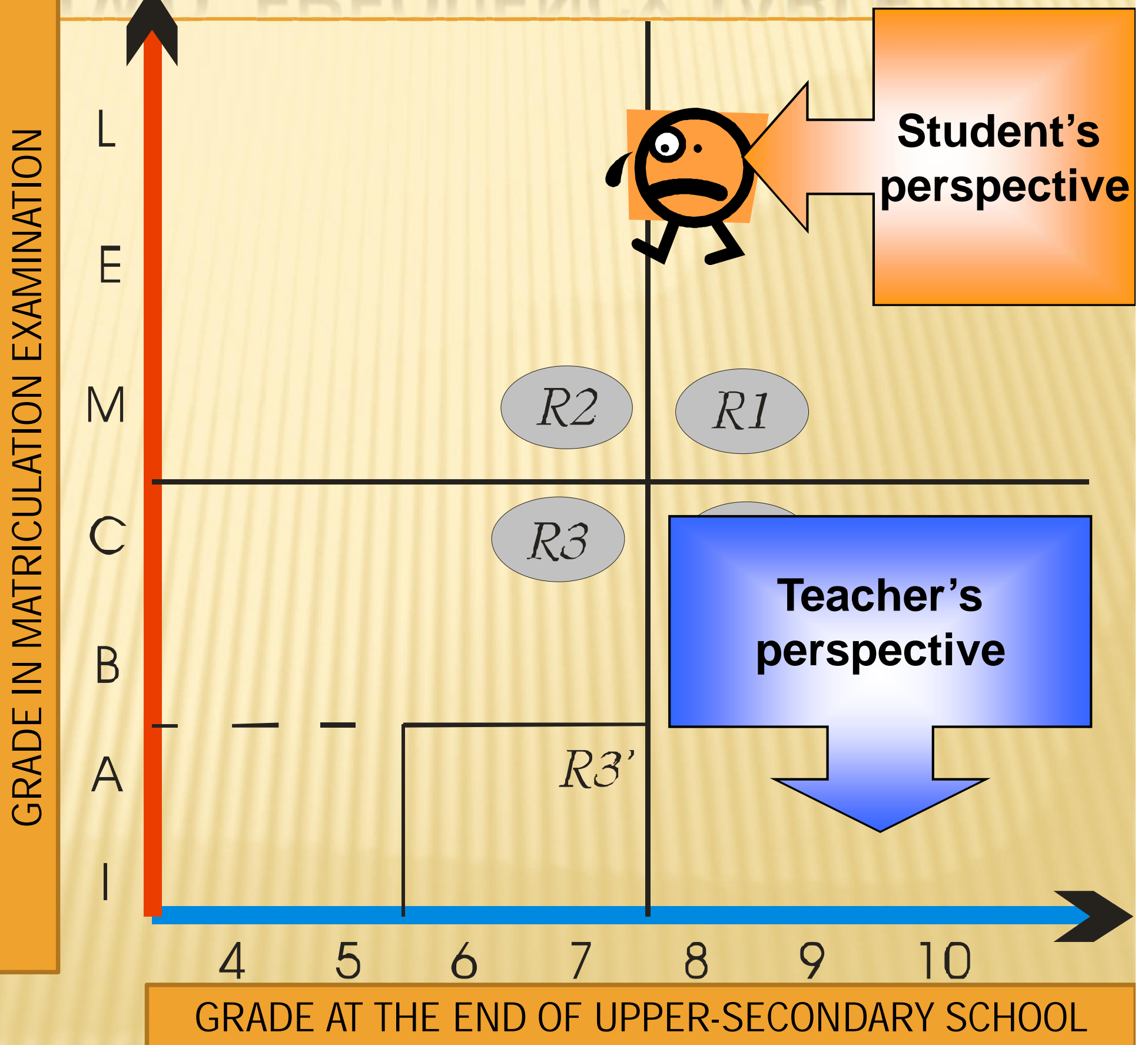




\section{- Introduction}

- Theoretical framework

- Aim and perspectives

- Results 


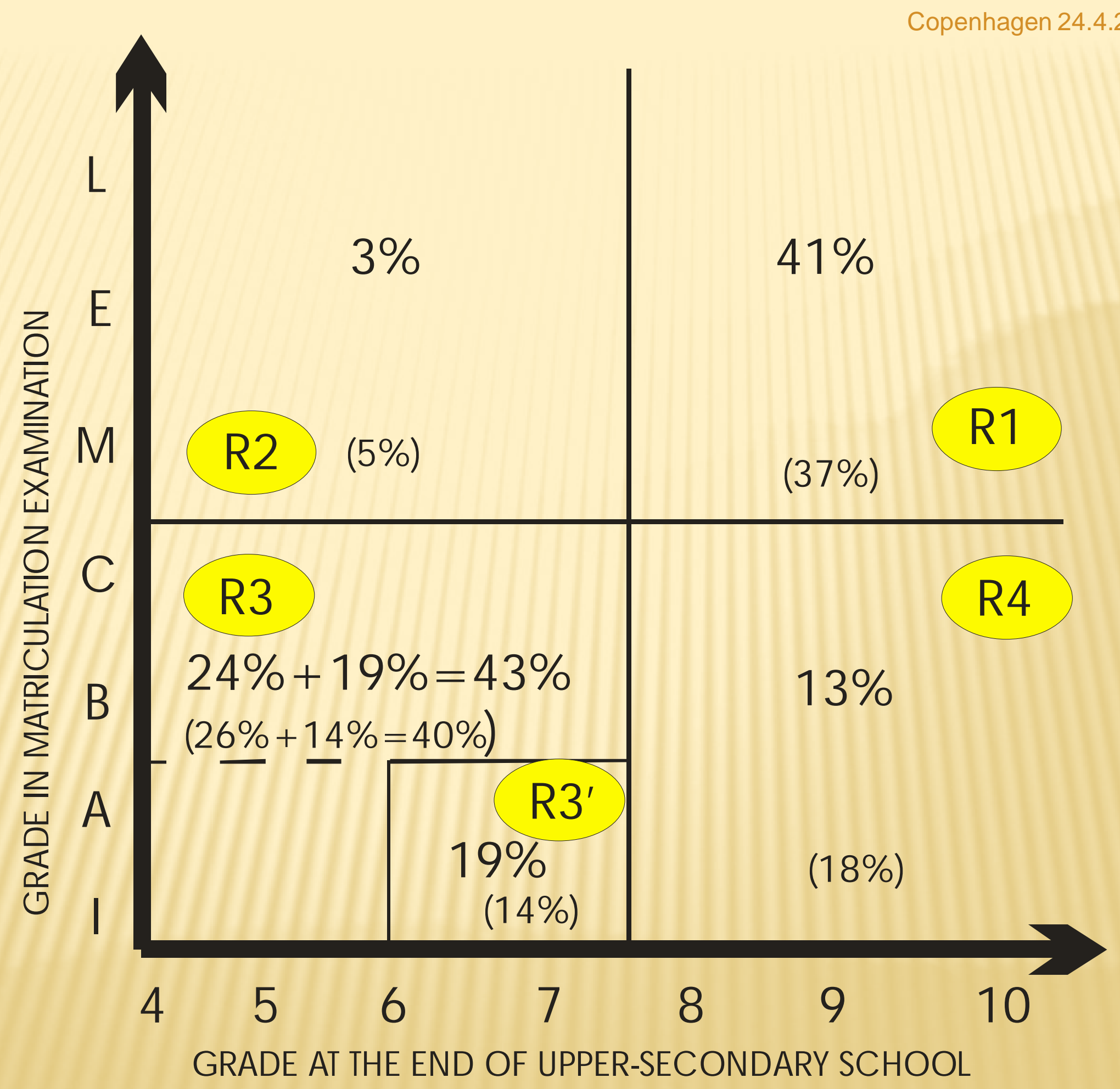




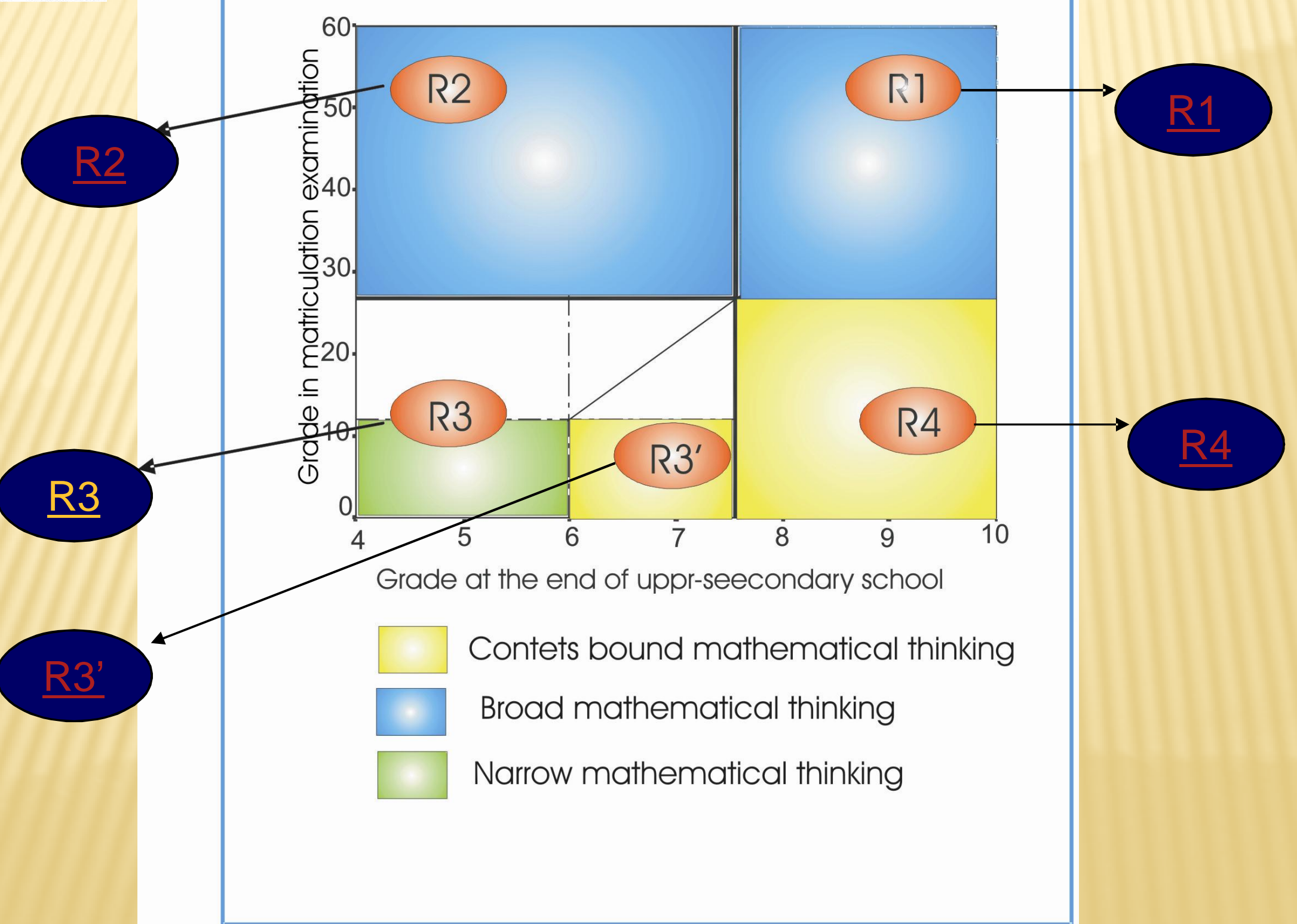




\section{R1 "SUCCESSFUL STUDENTS"}

UNIVERSITY

"Five features of their mathematical proficiency are well developed.

" appreciate mathematics as an important and pleasent subject.

"have perseverance to struggle with complex mathematical problems. broad mathematical thinking 


\section{R2 "MATURE STUDENTS"}

UNIVERSITY

"They had difficulties in mathematics courses, but they studied hard and their mathematical proficiency developed just before matriculation examination. (especially procedural fluency)

They have perseverance to struggle with complex mathematics problems.

Broad mathematical thinking 


\section{R3 "'JUST DOING' STUDENTS"}

UNIVERSITY

concentrated on procedural fluency.

"felt that there was too fast tempo in mathematics lessons and therefore they didn't understand new concepts deeply.

self-confidence in mathematics was weak Narrow mathematical thinking 


\section{R3' "LOSERS"}

UNIVERSITY

"Most students ín the "losers" - group choiced mathematics as an optional test and they had concentrated on compulsory tests (calculation: optimize result, minimize work) quite good base (grade 6 or 7 ) in mathematics to develope their mathematical proficiency if they just had studied more systematically

self-confidence in mathematics was weak narrow mathematical thinking 


\section{R4 "DISAPPOINTED STUDENTS"}

UNIVERSITY

"have to know in advance for successful solving to what area of mathematics the problem belongs (undeveloped metacognitive skills in mathematics)

managed well in courses which consist of specific area of mathematics and they feel themselves good in mathematics (before matriculation examination)

contents bound mathematical thinking 


\section{REFERENCE}

[1] Sternberg, R. 1996. What is mathematical thinking? In R. Sternberg \& T. BenZeev (eds.) The nature of mathematical thinking. Mahwah (N) ): Erlbaum, 303-318. [2] Bereiter, C. 2002. Education and mind in the knowledge age. Mahwah (NJ): Erlbaum.

[3] Hiebert, J. \& Lefevre, P. 1986. Conceptual and procedural knowledge in mathematics: an introductory analysis. Teoksessa J. Hiebert (eds.) Conceptual and procedural knowledge: the case of mathematics. Hillsdale (NJ): Lawrence Erlbaum, $1-27$.

[4] McLeod, D. B. 1992. Research on affect in mathematics education: a reconceptualisation. In D. A. Grows (eds.) Handbook of research mathematics teaching and learning. London: Mcmillan Publishing Co, 575-596.

[5] Pehkonen, E. 1998. On the concept "mathematical belief". In E. Pehkonen \& G. Törner (eds.) The state-of-art in mathematics-related belief research. Results of the MAVI activities. University of Helsinki. Department of Teacher Education. Research report 195, 37-72.

[6] Schoenfeld, A. 1985. Mathematical problem solving. Orlando: Academic Press.

[7 ]Kilpatrick, J., Swafford, J. \& Findell, B. (eds.) 2001. Adding it up. Washington DC: National Academy Press. 